\title{
Modeling the Hydroclimatology of Kuwait: The Role of Subcloud Evaporation in Semiarid Climates
}

\author{
Marc P. Marcella and Elfatih A. B. Eltahir \\ Massachusetts Institute of Technology, Cambridge, Massachusetts
}

(Manuscript received 27 June 2007, in final form 9 October 2007)

\begin{abstract}
A new subcloud layer evaporation scheme is incorporated into Regional Climate Model, version 3 (RegCM3), to better simulate the rainfall distribution over a semiarid region around Kuwait. The new scheme represents subcloud layer evaporation of convective as well as large-scale rainfall. Model results are compared to observations from rain gauge data networks and satellites. The simulations show significant response to the incorporation of subcloud layer evaporation as a reduction by as much as $20 \%$ in annual rainfall occurs over the region. As a result, the new model simulations of annual rainfall are within $15 \%$ of observations. In addition, results indicate that the interannual variability of rainfall simulated by RegCM3 is sensitive to the specification of boundary conditions. For example, forcing RegCM3's lateral boundary conditions with the 40-yr ECMWF Re-Analysis (ERA-40) data, instead of NCEP-NCAR's Reanalysis Project 2 (NNRP2), reduces interannual variability by over $25 \%$. Moreover, with subcloud layer evaporation incorporated and ERA-40 boundary conditions implemented, the model's bias and root-mean-square error are significantly reduced. Therefore, the model's ability to reproduce observed annual rainfall and the year-to-year variation of rainfall is greatly improved. Thus, these results elucidate the critical role of this natural process in simulating the hydroclimatology of semiarid climates. Last, a large discrepancy between observation datasets over the region is observed. It is believed that the inherent characteristics that are used to construct these datasets explain the differences observed in the annual and interannual variability of Kuwait's rainfall.
\end{abstract}

\section{Introduction}

With low annual rainfall and long, hot summers, the Middle East has long been plagued by the scarcity of water resources (Mageed 1994). Combined with few natural freshwater sources, Kuwait's situation is particularly difficult. Within the last three decades, the nation's population has nearly doubled, while domestic water demand has nearly tripled (Fadlelmawla and AlOtaibi 2005). Recent reports indicate that Kuwaiti domestic water consumption now totals over $400 \mathrm{~L} \mathrm{day}^{-1}$ per capita (Al-Rashed and Sherif 2000). Further work has shown that the pattern of water consumption in the country is well correlated with atmospheric conditions such as temperature, relative humidity, and rainfall (Mukhopadhyay et al. 2000). In sharp contrast, extreme rainfall events, like that which occurred in Kuwait City

Corresponding author address: Marc Pace Marcella, Ralph M. Parsons Laboratory, Dept. of Civil and Environmental Engineering, Building 48-216, MIT, 77 Massachusetts Avenue, Cambridge, MA 02139.

E-mail: marcpace@mit.edu on 11 November 1997, can cause excessive rainfall (greater than $100 \mathrm{~mm}$ ) in just hours, resulting in large surface runoff and property damage (Al-Rashed and Sherif 2000). Therefore, it is important to study the spatial and temporal distribution of rainfall in this country. No prior studies have been published on modeling the rainfall distribution or the climate of Kuwait.

Furthermore, to allow for the future assessment of climate variability of Kuwait, this paper presents a modified regional climate model that more accurately simulates the rainfall over semiarid regions. Prior studies, in different versions of Regional Climate Model ( $\operatorname{RegCM})$, have indicated that the neglect of subcloud rainfall evaporation leads to an overestimation of rainfall in semiarid climates (Small et al. 1999 use of RegCM2). Additionally, in a recent paper, Evans et al. (2004) use RegCM3 to study rainfall processes over the Middle East. Their results show an overestimation of rainfall in Saudi Arabia and the Persian Gulf region, which they hypothesize may result from the model's failure to simulate the effects of evaporation. Recently, Worden et al. (2007) reaffirmed the significance of raindrop evaporation, reporting that nearly $20 \%$ (to as 
much as $50 \%$ ) of rainfall evaporates near convective clouds over the tropics. Here, we incorporate a more physically realistic representation of subcloud layer evaporation in a regional climate model. In addition, we show the importance of lateral boundary conditions in studying the distribution of rainfall over Kuwait. We compare simulation results to a variety of observational datasets to determine the effects of subcloud layer evaporation and lateral boundary conditions on the simulation of rainfall over Kuwait. Ultimately, this work should lead to better simulation and prediction of rainfall distribution over Kuwait and the surrounding region.

\section{Model description and development}

\section{a. Model description}

In this study, RegCM3 is used to study the role of subcloud evaporation on rainfall in semiarid climates. Several studies have been carried out using RegCM3, as referenced in Giorgi et al. (1998). Originally developed at the National Center for Atmospheric Research (NCAR) and now maintained at the International Center for Theoretical Physics (ICTP), RegCM3 is a threedimensional, hydrostatic, compressible, primitive equation, $\sigma$-vertical coordinate regional climate model. RegCM3 maintains much of the dynamical core of the fifth-generation Pennsylvania State University-NCAR Mesoscale Model (MM5; Grell et al. 1994). The model now employs NCAR's Community Climate Model, version 3 (CCM3), radiative transfer package (Kiehl et al. 1996). In addition, land surface physics are modeled by the Biosphere-Atmosphere Transfer Scheme version 1e (BATS1e) of Dickinson et al. (1993), while boundary layer physics are modeled by Holtslag et al.'s (1990) nonlocal planetary boundary layer scheme (see Giorgi et al. 1993a). RegCM3 also employs Zeng's bulk aerodynamic ocean flux parameterization, where sea surface temperatures (SSTs) are prescribed (Zeng et al. 1998). In addition, three different convection schemes (Kuo, Grell, and Emanuel) are available for nonresolvable rainfall processes (Giorgi et al. 1993b). After some experimentation with other convection schemes, the Kuo scheme best simulated the magnitude as well as spatial distribution of rainfall and thus was chosen for our experiments. Finally, RegCM3 includes a largescale, resolvable, nonconvective moisture scheme: the subgrid explicit moisture scheme (SUBEX; Pal et al. 2000). Because in this study subcloud evaporation was either added or improved in both the Kuo scheme and SUBEX, a more detailed description of both will be provided in the next section. The authors refer readers to Pal et al. (2007) for the most current developments and description of RegCM3.

\section{b. Model developments}

\section{1) LARGE-SCALE SUBCLOUd EVAPORATION: SUBEX}

Since one of the focuses of this paper is on the improvement of SUBEX's raindrop evaporation, we briefly describe the precipitation process in the scheme. RegCM3's large-scale rainfall evaporation is modified by improving the representation of the evaporation rate coefficient. SUBEX dramatically improves RegCM3's representation of clouds, rainfall, and the energy budget (Pal et al. 2000). As in the work of Pal et al. (2000), large-scale rainfall $P^{\mathrm{LS}}$ forms in RegCM3 once cloud water content $Q_{c}^{\mathrm{LS}}$ breaches the autoconversion threshold $Q_{c}^{\text {th }}$ as follows:

$$
P^{\mathrm{LS}}=C_{\mathrm{ppt}}\left(\frac{Q_{c}^{\mathrm{LS}}}{\mathrm{FC}^{\mathrm{LS}}}-Q_{c}^{\mathrm{th}}\right) \mathrm{FC}^{\mathrm{LS}} \quad\left(\mathrm{kg} \mathrm{kg}^{-1} \mathrm{~s}^{-1}\right),
$$

where $\mathrm{FC}^{\mathrm{LS}}$ is the fraction of the grid cell covered by clouds, which is a function of the average relative humidity of the grid cell (Sundqvist et al. 1989), and $C_{\mathrm{ppt}}\left(\mathrm{s}^{-1}\right)$ is the inverse of the characteristic time it takes cloud droplets to convert into raindrops, the autoconversion rate. The cloud water threshold $Q_{c}^{\text {th }}$ $\left(\mathrm{kg}_{\text {water }} \mathrm{kg}_{\text {air }}{ }^{-1}\right)$, is described by an empirical function of temperature. In addition, the scheme accounts for raindrop accretion, which was previously excluded from RegCM3's explicit moisture scheme. As formulated in the work of Sundqvist et al. (1989), raindrop evaporation, which occurs in the cloud-free portion of the grid cell, is modeled as

$$
P_{k, \text { evap }}=C_{\text {evap }}(1-\mathrm{RH}) \sqrt{P_{\text {sum }, k}} \quad\left(\mathrm{~kg} \mathrm{~kg}^{-1} \mathrm{~s}^{-1}\right),
$$

where $\mathrm{RH}$ is the ambient relative humidity and $P_{\text {sum }}$ $\left(\mathrm{kg} \mathrm{m}^{-2} \mathrm{~s}^{-1}\right)$ is the large-scale precipitation falling from above and is uniformly distributed across the grid box. The evaporation rate coefficient $C_{\text {evap }}$, the focus of the improvement proposed in this paper, will be referred to as the static evaporation coefficient. The moisture and heat tendencies are updated for each layer to account for the amount of rainwater evaporated within that layer. Thus, rainfall leaving a grid cell at vertical level $k$ (where $k$ increases as one moves toward the surface) is simply

$$
\begin{aligned}
P_{k}^{\mathrm{LS}} & =P_{k-1}^{\mathrm{LS}}-P_{k, \text { evap }} \quad\left(\mathrm{kg} \mathrm{kg}^{-1} \mathrm{~s}^{-1}\right) ; \\
P_{\text {sum }, k} & =P_{k-1}^{\mathrm{LS}} .
\end{aligned}
$$


TABLE 1 . Summary of SUBEX constants used.

\begin{tabular}{lcc}
\hline \multicolumn{1}{c}{ Parameter } & Value & Units \\
\hline Autoconversion rate $C_{\mathrm{ppt}}$ & $5 \times 10^{-4}$ & $\mathrm{~s}^{-1}$ \\
Autoconversion scale factor $C_{\mathrm{acs}}$ & $4 \times 10^{-1}$ & - \\
Accretion rate $C_{\mathrm{acc}}$ & 6.0 & $\mathrm{~m}^{3} \mathrm{~kg}^{-1} \mathrm{~s}^{-1}$ \\
Static coefficient of evaporation & $2 \times 10^{-5}$ & $\left(\mathrm{~kg} \mathrm{~m}^{-2} \mathrm{~s}^{-1}\right)^{-1 / 2} \mathrm{~s}^{-1}$ \\
$C_{\text {evap }}$ & & \\
\hline
\end{tabular}

Following the work of Georgakakos and Bras (1984) in their formulation of rainfall evaporation in a hydrological station model, we propose here to scale SUBEX's $C_{\text {evap }}$ to account for the variability of water vapor diffusivity as a function of the model layer's temperature and pressure. Our assumed form of dependence of the diffusion coefficient on temperature and pressure is based on the empirical analysis of Pruppacher and Klett (1978). Thus, our new rate coefficient, which will be referred to throughout as the dynamic evaporation coefficient, is

$$
C_{\text {evap }}^{\prime}=C_{\text {evap }}\left(\frac{T_{o}}{T^{*}}\right)^{1.94}\left(\frac{P^{*}}{P_{o}}\right) \quad\left(\mathrm{kg} \mathrm{m}^{-2} \mathrm{~s}^{-1}\right)^{-1 / 2} \mathrm{~s}^{-1},
$$

where $P^{*}$ and $T^{*}$ take values of $1013.25 \mathrm{mb}$ and $273.15 \mathrm{~K}$, respectively, and $P_{o}$ and $T_{o}$ are values for each atmospheric layer. On a typical winter day (when most largescale rainfall occurs in Kuwait), the surface temperature is about $25^{\circ} \mathrm{C}$ and surface pressure reaches approximately $1000 \mathrm{mb}$ (Al Kulaib 1984). As a result, in such an environment, using the new dynamic $C_{\text {evap }}$ in lower model layers can increase evaporation by more than $20 \%$ compared to the original SUBEX raindrop evaporation formulation. Table 1 provides all prescribed constant SUBEX parameters used in our experiment.

\section{2) Convective subcloud evaporation: KuO SCHEME}

As mentioned by Sundqvist et al. (1989), most convection schemes lack subcloud evaporation since it is assumed that rain falls through almost saturated air. However, in semiarid climates this is not the case. Studies have shown that in these regions between $25 \%$ and $50 \%$ of convective rainfall can evaporate before reaching the ground, depending on rainfall intensity and cloud-base height (Rosenfeld and Mintz 1988). Further work by Al Kulaib (1984) describes many accounts in which such convective activity occurs over Kuwait with rainfall totals less than $5 \mathrm{~mm}$. As a result, to accurately simulate the rainfall over Kuwait, it is necessary to include a subcloud convective evaporation scheme. Modeled after SUBEX's layer-by-layer approach for evaporation, the method applied here may also be adopted to other convection schemes. Although both the Grell and Emanuel schemes offered in RegCM3 do model some form of rainfall evaporation, as mentioned prior, Kuo's convective parameterization is used in these experiments because of its superior performance over our domain.

Triggered by a convectively unstable vertical sounding and large-scale moisture convergence, the Kuo scheme implements a simple, integrated column approach in representing convective rainfall (Kuo 1974). Rainfall is calculated from the following equation:

$$
P_{o}^{\mathrm{CU}}=M_{t}(1-\beta),
$$

where $M_{t}$ is the vertically integrated moisture convergence described by

$$
M_{t}=\left(\frac{m^{2}}{g}\right) \int_{0}^{1} \frac{\nabla p^{*} \dot{V} q_{v}}{m} d \sigma,
$$

where $m$ is the mass flux, $g$ is acceleration due to gravity, $\nabla p^{*}$ is a function of surface and top of model pressure, $\dot{V}$ is dependent on horizontal velocity, $q_{v}$ is the mixing ratio of water vapor, and $\sigma$ is the vertical sigma level. The term $\beta$, the rainfall efficiency, is determined by the average relative humidity of the sounding $\overline{\mathrm{RH}}$ as follows:

$\beta=2(1-\overline{\mathrm{RH}})$ for $\overline{\mathrm{RH}} \geq 0.5 ; \quad$ otherwise, $\quad \beta=1$.

Similar to SUBEX evaporation, we permit rainfall evaporation to occur from the model's cloud-base level down to the surface as described in Eq. (2) while using the dynamic coefficient of evaporation of Eq. (5). Because rainfall in the Kuo scheme is calculated in a columnintegrated approach, we assume that $P_{o}^{\mathrm{CU}}$ is the total rainfall at the cloud-base level as calculated in Eq. (6). We then permit evaporation to occur layer by layer from this initial amount as follows:

$$
P_{k}^{\mathrm{CU}}=P_{o}^{\mathrm{CU}}-P_{k, \text { evap }},
$$

where $k=$ cloud base and

$$
P_{k+1}^{\mathrm{CU}}=P_{k}^{\mathrm{CU}}-P_{k+1, \text { evap }}
$$

where

$$
P_{k+1, \text { evap }}=C_{\text {evap }}^{\prime}(1-\mathrm{RH}) \sqrt{P_{k}^{\mathrm{CU}}},
$$

and so forth, from $k=$ cloud base down to $k+1=$ surface. Again, it is important to note that moisture and heat tendencies are updated for each layer to account for water evaporated in that layer.

\section{Experimental design and observational datasets}

\section{a. Experimental setup}

Simulations using RegCM3 were completed spanning the period from 1982 to 2002. Our domain, centered at 


\section{GTOP030 Topography (m) \& GLCC Vegetation}

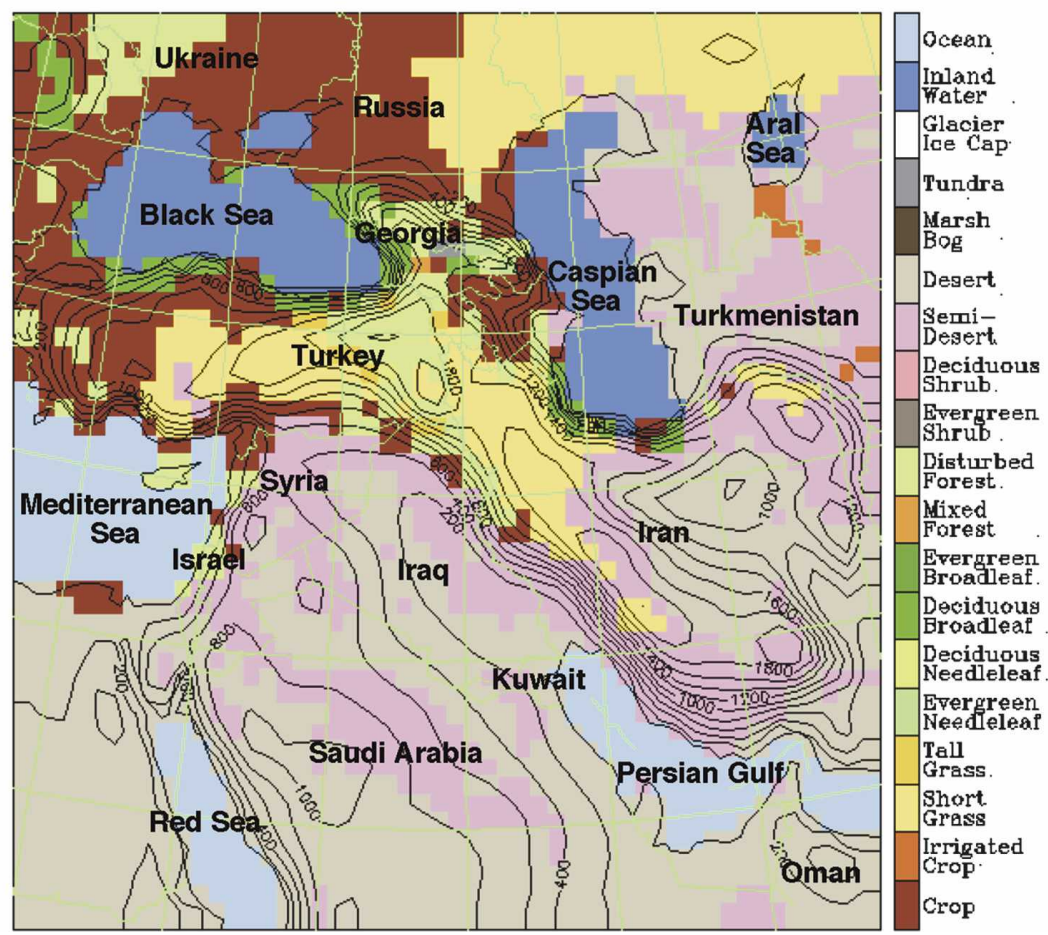

FIG. 1. Domain implemented for all simulations with topography contoured (200-m intervals) and vegetation shaded. Kuwait is classified by semidesert and desert land cover.

$33.5^{\circ} \mathrm{N}, 44^{\circ} \mathrm{E}$ at $60-\mathrm{km}$ resolution, has 52 points in the zonal and meridional direction using a Lambert conformal projection. Thus, the domain covers most of the Middle East from the Black and Aral Seas in the North to the Red Sea in the southwest and Oman in the southeast. Experiments were performed at finer resolutions $(30 \mathrm{~km})$, but results did not improve and computational expense became unrealistic. Figure 1 represents the model domain as well as topography and land use in the simulations. Two different sets of initial and boundary conditions are implemented and examined: $\mathrm{Na}-$ tional Centers for Environmental Prediction (NCEP)NCAR's Reanalysis Project 2 (NNRP2) of Kalnay et al. (1996) and the 40-yr European Centre for MediumRange Forecasts (ECMWF) Re-Analysis (ERA-40) of Uppala et al. (2005). Lateral boundary conditions (LBCs) were enforced by applying the exponential relaxation of Davies and Turner (1977). As mentioned prior, SSTs are prescribed to RegCM3 from the National Oceanic and Atmospheric Administration (NOAA) optimally interpolated SST (OISST) dataset, which has a temporal coverage from 1982 to 2002 (Reynolds 2002). The SST datasets are $1^{\circ} \times 1^{\circ}$ weekly resolution and are based on in situ and satellite observations.
To account for the local effects of LBCs on model results, the model's output from a strip with a width of $3^{\circ}$ along each boundary is not analyzed. Nonetheless, our results here will focus mostly on model output from $28.4^{\circ}$ to $30.2^{\circ} \mathrm{N}$ and from $46.5^{\circ}$ to $48.5^{\circ} \mathrm{E}$, the approximate location of Kuwait, which should be free from most LBC influences. Table 2 provides a summary of the simulations completed, the names that will be used to describe each run, and the datasets used in each experiment.

\section{b. Rainfall datasets}

For this study, a variety of rainfall datasets were considered such as the Tropical Rainfall Measuring Mission (TRMM) and NCEP reanalysis data. However, for rainfall measurements, we aim for a longer historical record than TRMM as well as an unbiased dataset (NNRP2 is used for boundary conditions). The Climatic Research Unit (CRU) high-resolution gridded dataset, TS 2.1, comprises a monthly time series of precipitation for the period of 1900 to 2002. Values are interpolated from surface observations onto a global $0.5^{\circ} \times 0.5^{\circ}$ resolution grid (Mitchell and Jones 2005) Many studies (e.g., Jiao and Caya 2006; Syed et al. 2006) have used the CRU rainfall dataset for climate 
TABLE 2. Summary of simulations with parameters varied. These names will be used to reference each run in the text.

\begin{tabular}{lcccc}
\hline \hline \multicolumn{1}{c}{ Run } & Years & LBC & Evaporation & SST \\
\hline NCEP & $1982-2002$ & NNRP2 & - & OISST \\
ECMWF & $1982-2002$ & ERA-40 & - & OISST \\
EEVP & $1982-2002$ & ERA-40 & Kuo + SUBEX & OISST \\
\hline
\end{tabular}

analysis and model validation. The Global Precipitation Climatology Project (GPCP), established in 1979 by the World Climate Research Programme (WCRP), combines a blend of satellite observations and rain gauge measurements to produce precipitation estimates. Satellite measurements computed from microwave imagers such as the Special Sensor Microwave Imager (SSM/ I), as well as infrared measurements like the Atmospheric Infrared Sounder (AIRS), are merged with rain gauge data, which are collected and maintained by the Global Precipitation Climatology Centre (Adler et al. 2003). The output is a monthly, global, total rainfall product of $2.5^{\circ} \times 2.5^{\circ}$ resolution from 1979 to present. Last, located at $29.13^{\circ} \mathrm{N}, 47.58^{\circ} \mathrm{E}$ in Kuwait City, the Kuwait International Airport has kept a nearly continuous record of monthly rainfall. Through the World Meteorological Organization (WMO) and the World Weather Records (WWR) compilation, these measurements are available from 1961 to present. Other station data exist within Kuwait, but none with such a substantial continuity in their observations. The airport station data, along with CRU and GPCP data, will be compared to simulations of monthly, annual, and interannual variability of rainfall in Kuwait.

\section{Results and discussion}

Several studies using RegCM to model the climate of arid regions have compared model results to reanalysis data. For example, Small et al. (1999) have shown that general circulation patterns such as $500-\mathrm{mb}$ geopotential heights and winds are well represented by RegCM2 over a similar domain in central Asia. In addition, Evans et al. (2002) have used RegCM3 to model the climate of the Middle East in a domain similar to that of this study. Their results show reasonable temperature representation in the model with a slight cool bias in winter. Similarly, we find a cool bias (of around $1^{\circ} \mathrm{C}$ ) over the entire domain. However, summer (JuneAugust) average temperatures show a warm bias. We are currently addressing this summer warm bias and results will be reported in the future.

\section{a. Model validation}

For baseline model performance, a comparison of NCEP's and ECMWF's annual rainfall distribution to
TABLE 3. Summary of observations and simulation results for the country of Kuwait and for Kuwait City International Airport. Mean $(\mu)$ annual rainfall in millimeters, interannual variability $(\sigma)$ in millimeters, and the coefficient of variation $C_{v}$ are presented.

\begin{tabular}{lccccccc}
\hline \hline & \multicolumn{3}{c}{ Kuwait (country) } & & \multicolumn{3}{c}{ Kuwait City Airport } \\
\cline { 2 - 4 } & $\mu(\mathrm{mm})$ & $\sigma(\mathrm{mm})$ & $C_{v}$ & & $\mu(\mathrm{mm})$ & $\sigma(\mathrm{mm})$ & $C_{v}$ \\
\hline CRU & 110 & 35 & 0.32 & & 100 & 40 & 0.39 \\
WMO & - & - & - & & 112 & 74 & 0.66 \\
GPCP & 188 & 81 & 0.43 & & 182 & 93 & 0.51 \\
NCEP & 154 & 119 & 0.77 & & 162 & 147 & 0.91 \\
ECMWF & 148 & 101 & 0.68 & & 143 & 113 & 0.79 \\
EEVP & 126 & 88 & 0.71 & & 122 & 106 & 0.87 \\
\hline
\end{tabular}

CRU observations is made here. To begin with, both simulations significantly overestimate Kuwait's annual rainfall, which CRU estimates at $110 \mathrm{~mm}$. More specifically, as shown in Table 3, NCEP overpredicts annual totals by over $40 \%$ at $154 \mathrm{~mm} \mathrm{yr}^{-1}$, and ECMWF simulates $148 \mathrm{~mm}$, which is $35 \%$ too wet. These values are still somewhat better than rainfall values in reanalysis datasets such as NNRP2 and ERA-40, which severely underestimate rainfall at 50 and $75 \mathrm{~mm} \mathrm{yr}^{-1}$, respectively. Nevertheless, when comparing CRU's annual rainfall (Fig. 2a) to NCEP and ECMWF annual rainfall (Figs. 2b and 2c), the model does well in simulating the spatial distribution of rainfall over the domain. For example, RegCM3 correctly simulates the gradient of rainfall from Kuwait to the Zagros Mountains of western Iran. However, attention should be paid to the extensive, excessive, wet tongue of rainfall that extends from central Saudi Arabia to the Persian Gulf.

This area is easily seen in Figs. 3a and 3b, which display the annual difference between CRU and RegCM3 rainfall. Some locations in this southern region have annual rainfall overestimated by more than $60 \mathrm{~mm}$, which is nearly double the yearly rainfall (see Fig. 3c). The neglect of subcloud layer evaporation contributes to these results, and thus addressing this problem should help reduce simulated values in the region. In addition, in both NCEP and ECMWF, rainfall over the Zagros Mountains is overestimated by nearly 300 $\mathrm{mm}$ or $75 \%$ more than observations as seen in Figs. $3 \mathrm{c}$ and $3 \mathrm{~d}$. On a similar note, the spatial distribution of rainfall across the Black Sea near Turkey and the Caspian Sea adjacent to Iran are modeled correctly but with magnitudes that are significantly overestimated. This amplification is caused by steep topography gradients that exist along the coastline of the Black and Caspian Seas where the Koroglu, Caucasus, and Elburz mountain ranges are located. With winds blowing onshore over topography of $1 \mathrm{~km}$ and higher, orographic lifting occurs with a constant, abundant supply of mois- 
CRU

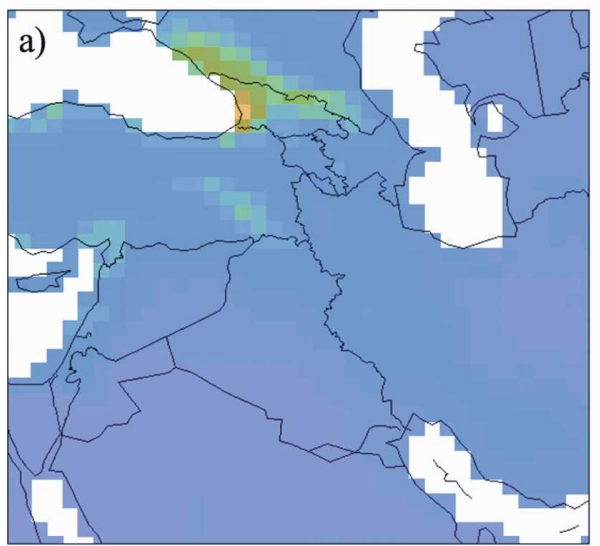

ECMW

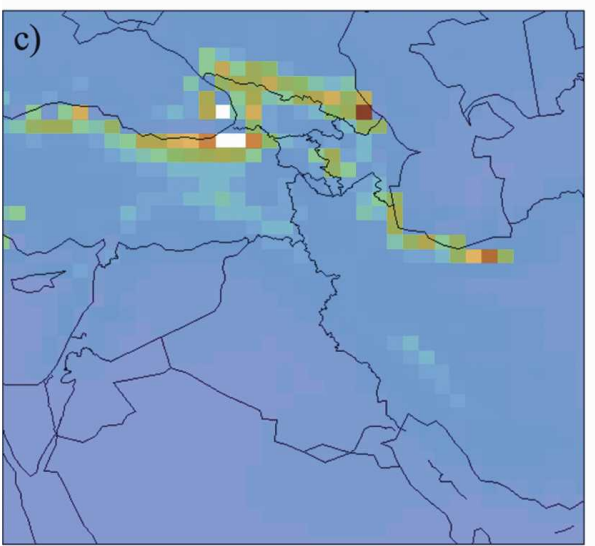

NCEP
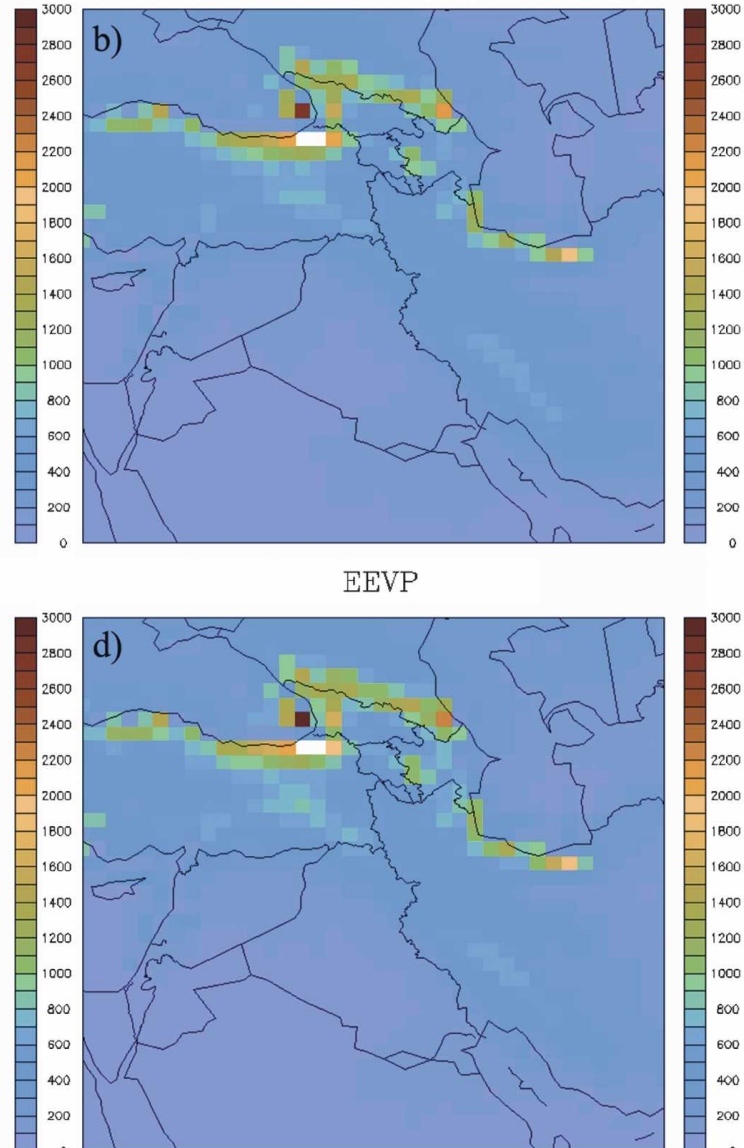

EEVP

\section{톨}

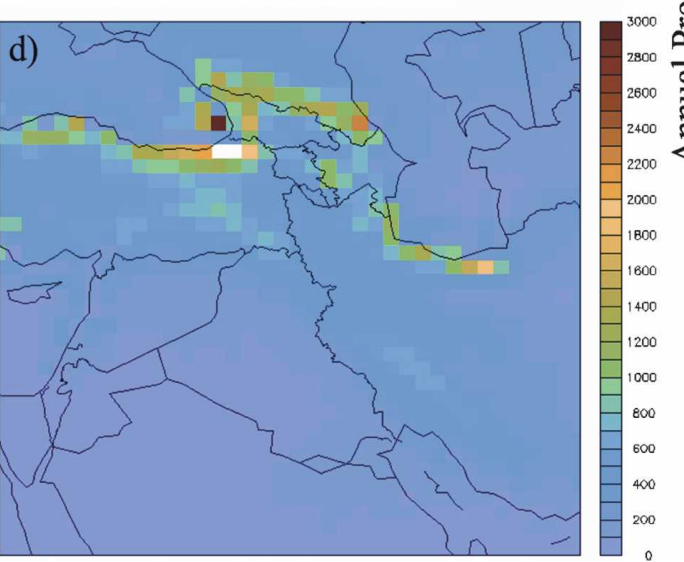

FIG. 2. Average annual rainfall (mm) from 1982 to 2002 for (a) CRU observations, (b) NCEP simulation, (c) ECMWF simulation, and (d) EEVP simulation.

ture that excessively precipitates out. The dry bias in RegCM3 along the eastern Mediterranean Coast and western Saudi Arabia is most likely a result of model resolution. At $60 \mathrm{~km}$, RegCM3 does not capture the finer-scale mountainous topography that exists in both areas, which enhances rainfall patterns. Finally, our analysis has shown that RegCM3 correctly simulates the seasonal cycle of Kuwait rainfall, where the rainy season begins in October and ceases in May (Fig. 4a). In addition, at a finer temporal resolution, the model does well in simulating actual rainfall events when compared to TRMM daily rainfall records, as shown in Fig. $4 \mathrm{~b}$.

\section{b. Effects of boundary conditions}

Figures 2 and 3 demonstrate that boundary conditions have very little effect on RegCM3's spatial distribution or magnitude of Kuwait rainfall. The similarities are apparent in Figs. 5a and 5b, which display the total and percent difference between NCEP and ECMWF annual precipitation. Yearly differences between the two simulations for Kuwait are only $6 \mathrm{~mm}$ and $4 \%$, respectively. However, as seen in Fig. 5a, ECMWF possesses significantly wetter annual rainfall in the northern portion of the domain. This increased precipitation is approximately $10 \%-20 \%$ more than NCEP results (Fig. 5b). ECMWF results are therefore closer to CRU observations in northern Turkey and Georgia as seen in Fig. 3b. This most likely results from ERA-40 transporting more moisture at the boundaries than NNRP2; thus, more rainfall occurs along this inflow boundary. In addition, ECMWF appears to be somewhat drier than NCEP in western Saudi Arabia (Fig. 5b). However, the actual difference in precipitation, shown in Fig. 5a, is less than $10 \mathrm{~mm}$ and therefore insignificant.

\section{1) Comparison to CRU}

RegCM3 results show substantial differences in interannual variability compared to measured values (see Table 3). That is, NCEP exhibits a large year-to-year variation in rainfall. Compared to CRU's interannual 
NCEP Bias

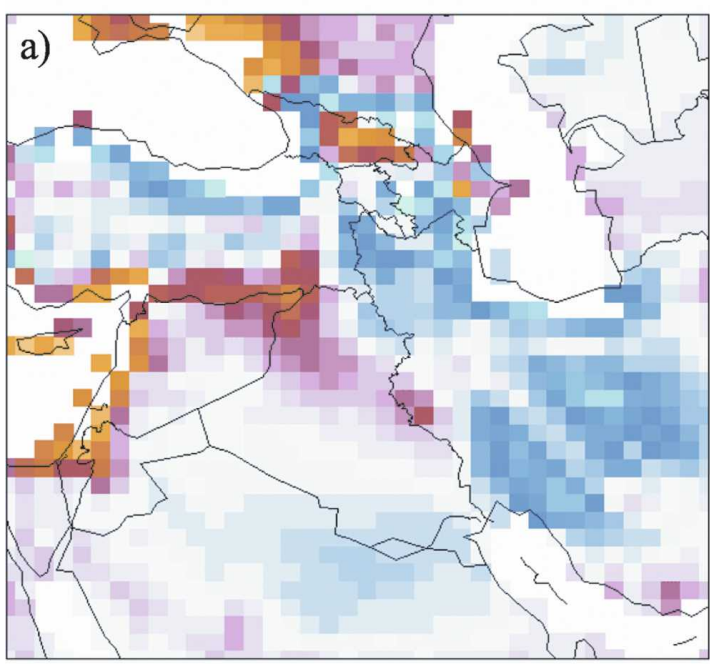

NCEP Percent Bias

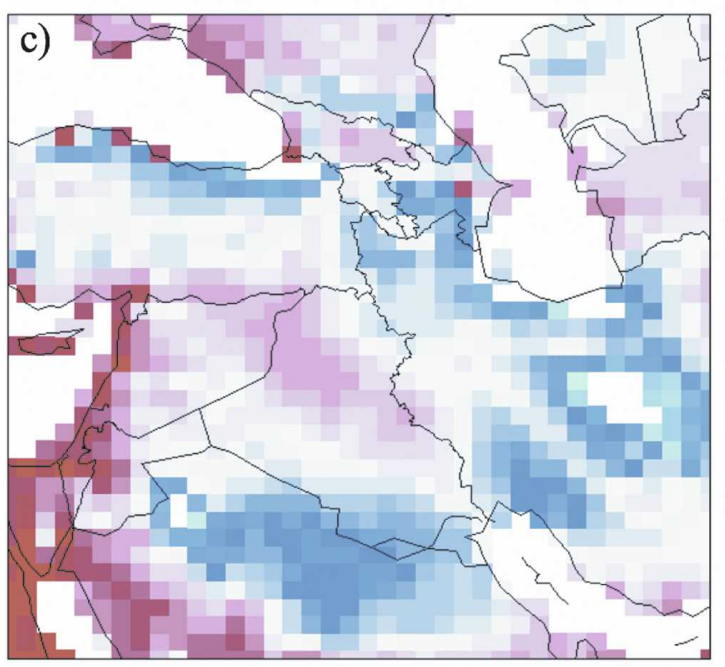

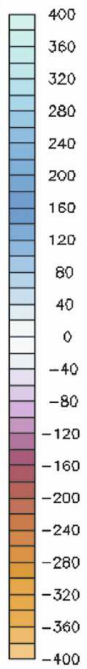
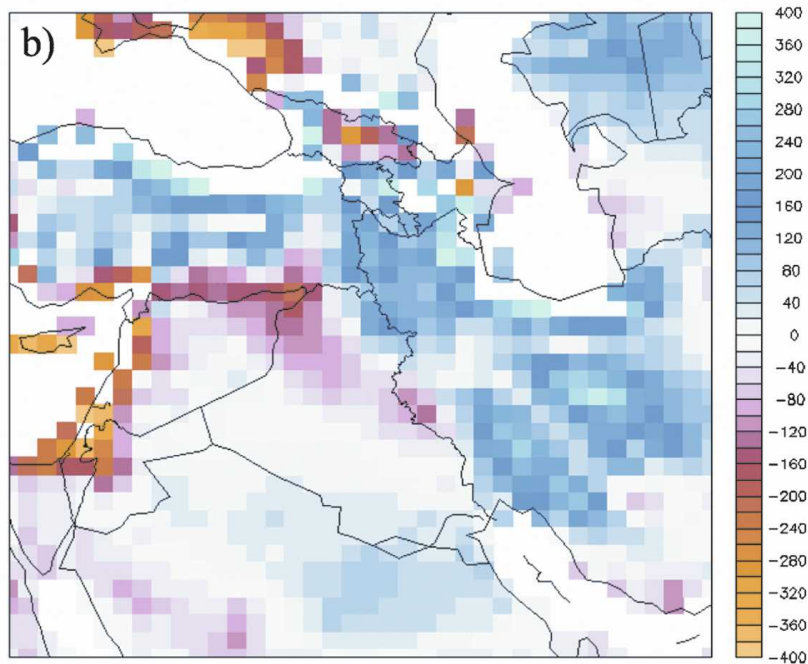

ECMW Percent Bias

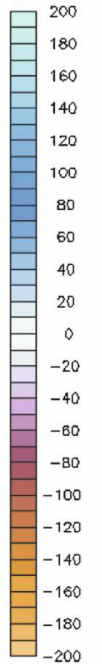

ECMW Bias

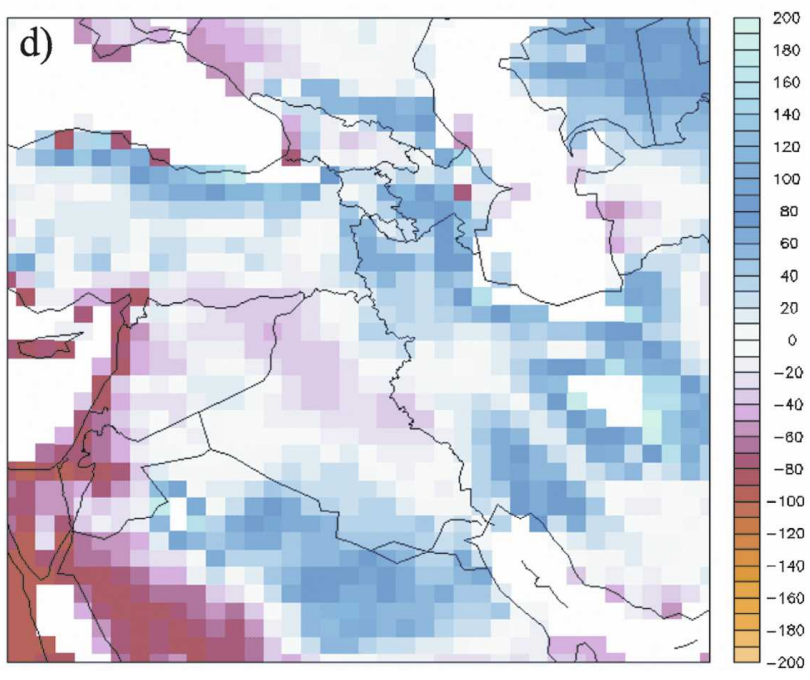

FIG. 3. Total annual precipitation difference ( $\mathrm{mm}$ ) between CRU and (a) NCEP and (b) ECMWF simulations for 1982-2002. Percent bias between CRU and (c) NCEP and (d) ECMWF. Red shaded areas (negative values) indicate locations where model results are drier than observations; blue shaded areas (positive values) indicate locations where model results are wetter than CRU observations.

variability (standard deviation) of $35 \mathrm{~mm}$, NCEP's value of $119 \mathrm{~mm}$ is nearly 2.5 times larger than observations. It should be noted that too much smoothing seems to occur in CRU estimates, which average the eight closest station observations to calculate each grid box's value. However, such large interannual variability suggests the model's inability to capture the year-toyear variation in rainfall. Similar results were found in Small et al. (1999), where overestimations in RegCM's annual rainfall led to overestimations in interannual variability for semiarid regions of central Asia. Likewise, the coefficient of variation $C_{v}$, which measures the dispersion of a distribution, is, as expected, significantly higher for NCEP at 0.77 versus 0.32 for CRU. It is important to note that all simulations have coefficients of variation approximately between 0.7 and 0.8 (Table 3 ). These quantities indicate that using the mean alone to describe model performance is not sufficient and that the interannual variability of rainfall is of particular importance. These wildly varying annual totals can also be seen in Fig. 6, where RegCM3 (NCEP shown) simulates the correct cycle of wet and dry years compared to observations but overestimates the magnitude for relatively wet years. Also noticeable in Fig. 6a is the muted variability in CRU compared to satellite measurements of rainfall from GPCP. Consequently, GPCP's interan- 

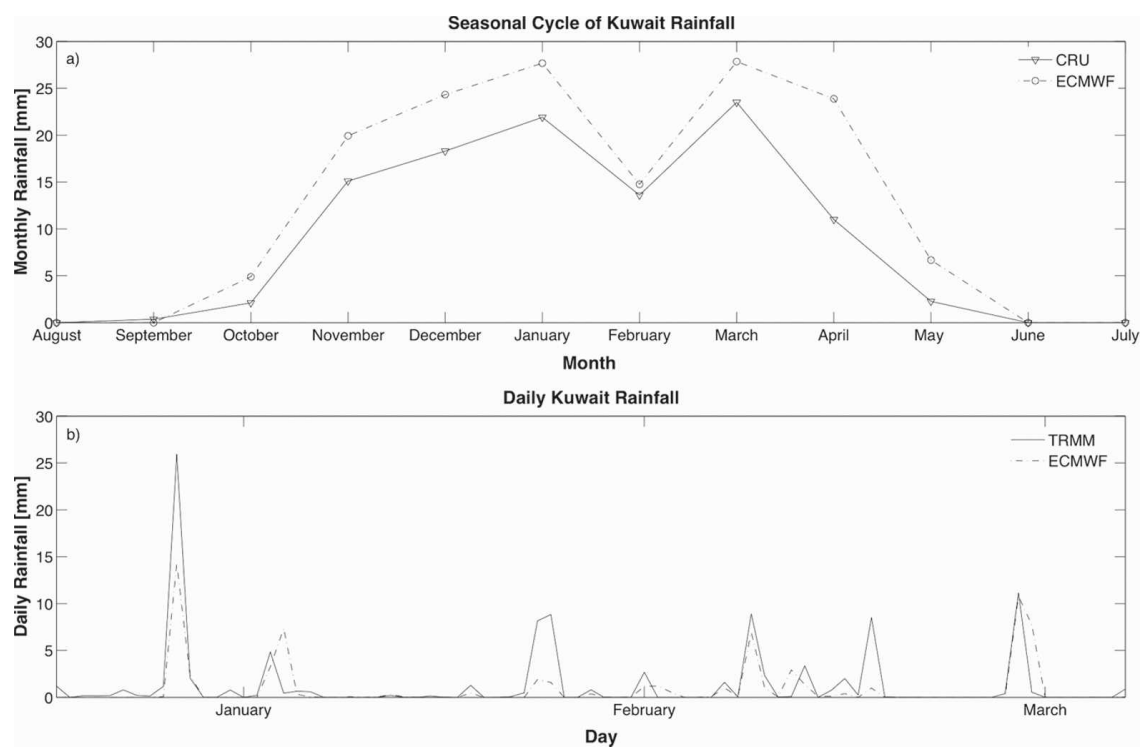

FIG. 4. Temporal plot of Kuwait's (a) average monthly rainfall (mm) for the period of 1982-2002 for CRU and ECMWF simulation and (b) daily rainfall (mm) from January to March 1999 for TRMM and ECMWF simulation.

nual variability is $81 \mathrm{~mm}$ compared to CRU's $35 \mathrm{~mm}$ (Table 3). Although it is important to note the coarse resolution of GPCP $\left(2.5^{\circ} \times 2.5^{\circ}\right)$, NCEP variability is still significantly larger than GPCP variability.

By forcing RegCM3 with ERA-40 boundary conditions, interannual variability is reduced in RegCM3 simulations. This reduction is better seen in Fig. 7, which shows model results plotted against observations (CRU and WMO) with the bias, root-mean-square error (rmse), and the slope of the best-fit line $(M)$ displayed. The model's bias describes how well it can reproduce observed mean conditions. The rmse provides an overall error of model simulations and hence better reflects how well the model reproduces year-to-year variations in rainfall. Because the rmse includes the bias within the statistic, an improvement to the bias usually results in an improvement to the rmse. If we assume linearity between model output and observations, the slope can be defined as the slope of the bestfit line of model output versus observations. A slope greater than one represents model results that overpredict yearly variability while a slope less than one represents an underestimation in interannual variability. Also included in Table 4 are the $y$ intercepts of these best-fit lines. Thus, an improvement to the bias, rmse, and slope indicates a model that can more accurately predict mean observational conditions as well as interannual variations in these observations. As seen in Fig. $7 \mathrm{a}$, the NCEP simulation exhibits a high rmse of 102.7 $\mathrm{mm} \mathrm{yr}^{-1}$, which, combined with a slope of 2.6 , makes it clear that this simulation does poorly in describing year-to-year variations in Kuwait rainfall. In fact, in wetter years (those with observations greater than 110 $\mathrm{mm}$ ) NCEP's slope is significantly larger than 2.6. By introducing ERA-40 LBCs, the rmse is reduced by 20 $\mathrm{mm} \mathrm{yr}^{-1}\left(82.7 \mathrm{~mm} \mathrm{yr}^{-1}\right)$ and the slope is reduced to 2.3 (Table 4). Moreover, ECMWF simulates wetter years for those in which NCEP is drier than CRU (see Fig. 7b). Conversely, ECMWF simulates drier years for those in which NCEP is significantly wetter than CRU values. Both improvements contribute to a reduction in interannual variability by $15 \%$. Therefore, ECMWF better captures year-to-year variations in Kuwait rainfall.

\section{2) Comparison to WMO}

Due to the large discrepancy in CRU and GPCP values, we compare Kuwait International Airport's (Kuwait City) rain gauge data to the closest grid box in observations and model simulations. Looking at WMO comparisons (Fig. 7d), NCEP performs somewhat better at Kuwait City with an rmse of $92.7 \mathrm{~mm} \mathrm{yr}^{-1}$ and a slope of 1.9. However, with an interannual variability of $147 \mathrm{~mm}$, NCEP's standard deviation is still 2 times that of WMO. The improvement in rmse and slope is most likely due to the larger variability in the WMO rainfall record. That is, WMO has an interannual variability of $74 \mathrm{~mm}$, which is nearly double that of CRU, thus providing evidence that CRU values are in fact too smoothed. For example, Fig. 6b shows that CRU's annual rainfall for Kuwait City is significantly smaller than that reported by WMO, particularly in relatively 
ECMW-NCEP $[\mathrm{mm}]$

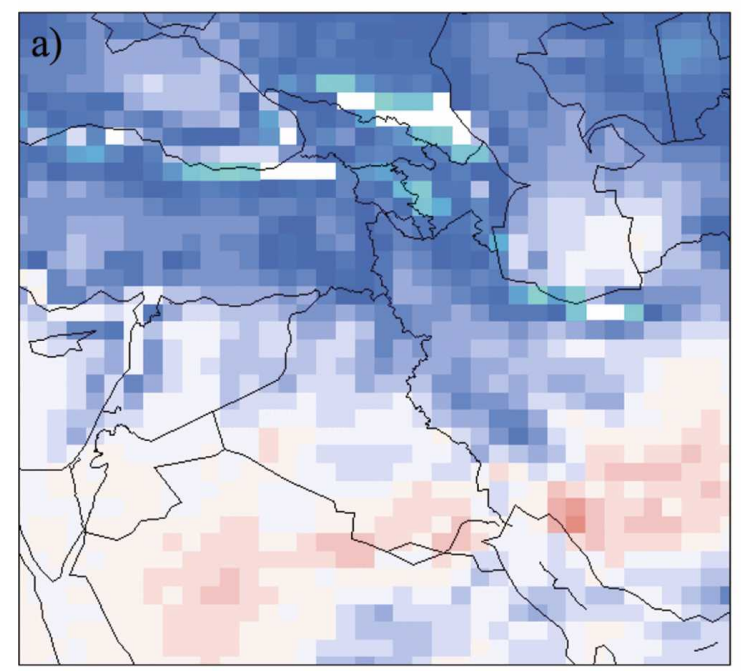

ECMW-EEVP $[\mathrm{mm}]$

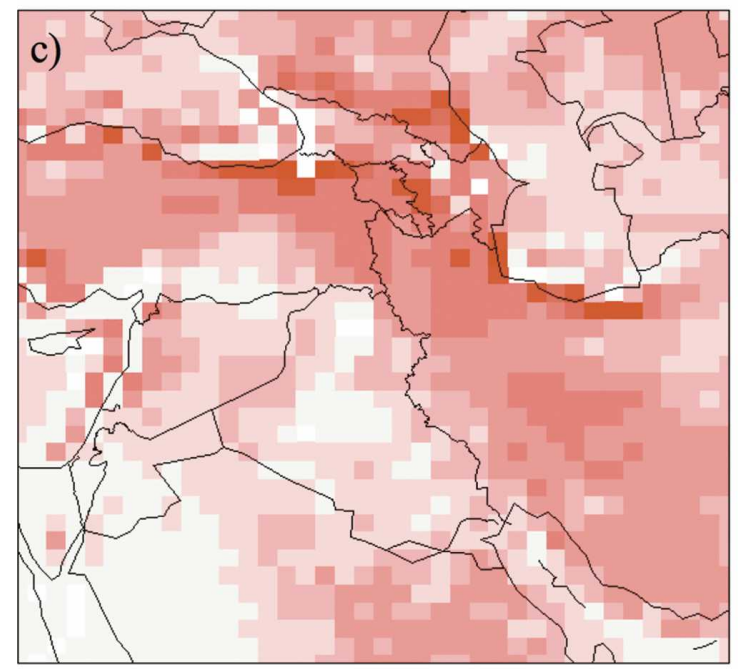

ECMW-NCEP [\%]
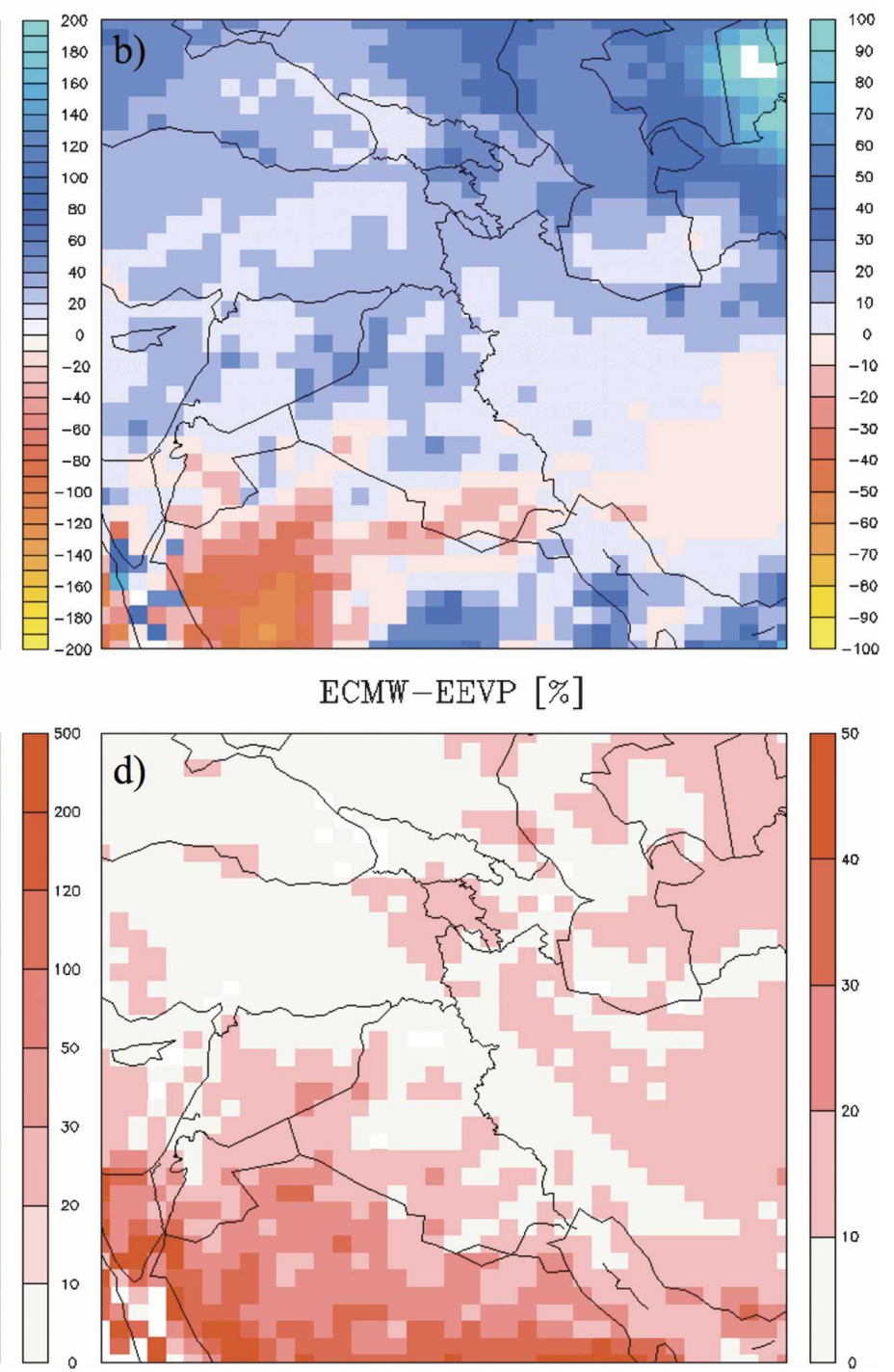

FIG. 5. Annual precipitation difference between ECMWF and NCEP simulations highlighting boundary condition effects in (a) total annual difference $(\mathrm{mm})$ and (b) percent difference. Also shown are annual precipitation differences between ECMWF and EEVP, highlighting effects of evaporation changes in (c) total annual difference (mm) and (d) percent difference.

wet years such as 1992, 1995, and 1997. Moreover, as expected, WMO exhibits a larger $C_{v}$ of 0.66 than CRU, 0.39 . An explanation as to why the CRU, GPCP, and WMO values differ so greatly is offered below in section 5. In any event, ECMWF performs significantly better, with a bias lower by nearly $20 \mathrm{~mm} \mathrm{yr}^{-1}$ and a rmse of only $59.6 \mathrm{~mm} \mathrm{yr}^{-1}$. The slope of the best fit line is much closer to unity at 1.4 , thus capturing year-toyear variations in Kuwait City rainfall better than NCEP. This improvement is further seen in the interannual variability of ECMWF, which is $25 \%$ smaller than NCEP at $113 \mathrm{~mm}$. It is believed that the large reduction in magnitude of extreme rainfall events in
ECMWF contributes the most to this improvement. For instance, in 1997, NCEP predicted nearly $425 \mathrm{~mm}$ of rainfall while for the same year ECMWF only simulated $340 \mathrm{~mm}$, an amount that is nearly $20 \%$ less. Thus, with a smaller bias, a $37 \%$ reduction in rmse, and a slope closer to unity, ECMWF more accurately simulates the rainfall distribution of Kuwait City.

\section{c. Effects of subcloud layer evaporation}

As discussed prior, RegCM3 forced with either NCEP or ECMWF boundary conditions significantly overestimates Kuwait's rainfall (Fig. 3). This can also be seen in Table 3 where an overestimation in Kuwait 


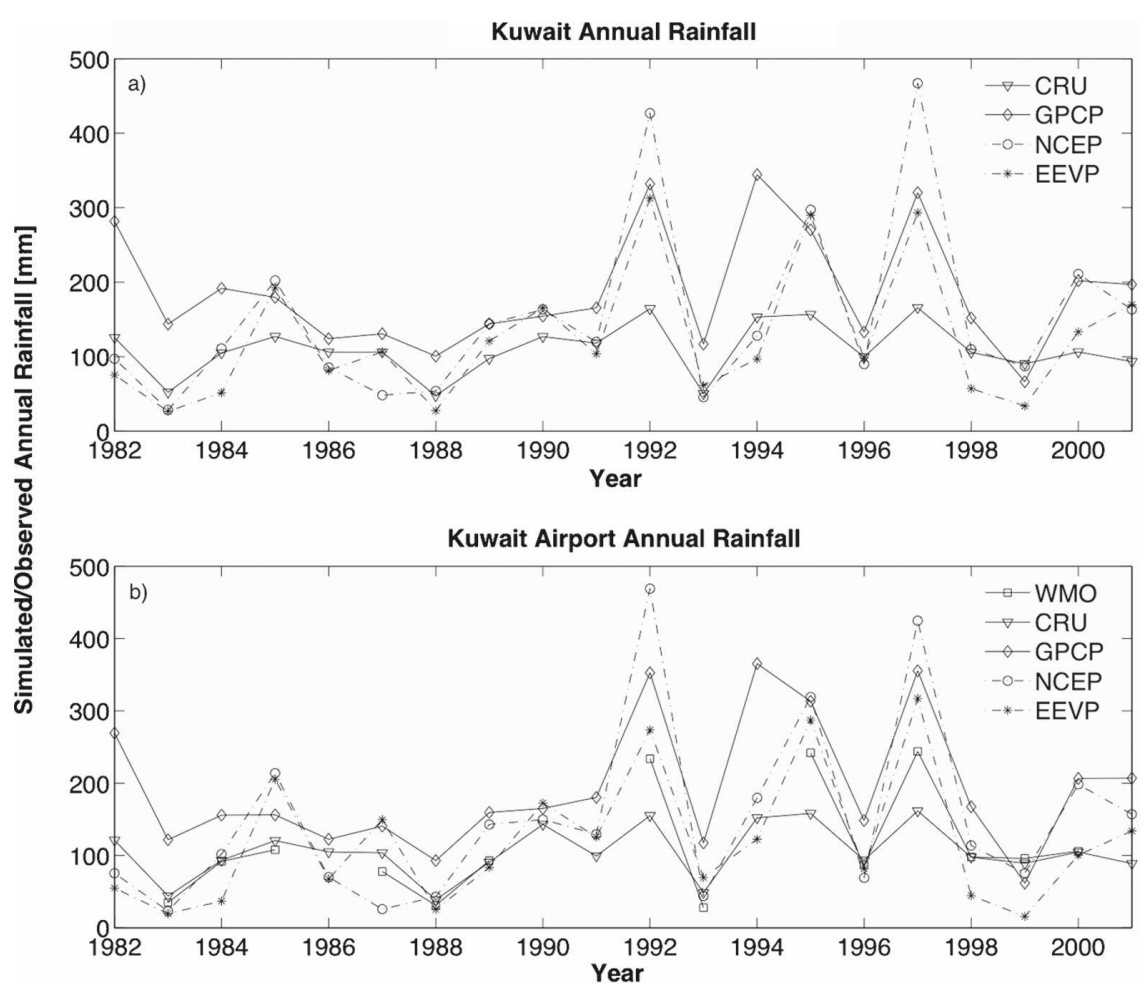

FIG. 6. Time series (1982-2002) of annual rainfall (mm) for (a) the country of Kuwait, including CRU, GPCP observations, NCEP simulation, and EEVP simulation, and (b) Kuwait City for same datasets plus WMO airport rain gauge.

annual rainfall by 44 and $38 \mathrm{~mm}$ occurs, respectively. Even though using ERA-40 boundary conditions reduces the interannual variability of the model, a large wet bias over Kuwait still exists. By both improving the large-scale rainfall evaporation rate coefficient and introducing subcloud layer rainfall evaporation in the convection scheme, a significant reduction in annual rainfall occurs, as seen in Fig. 5c. It is important to note that although the same daily rainfall events occur in Kuwait for both ECMWF and EEVP, it is the magnitude of the rainfall associated with any of these events that is significantly reduced in EEVP. Additionally, results indicate that using the dynamic evaporation coefficient does not markedly modify the spatial distribution of rainfall across the entire domain as well as over Kuwait (see Fig. 2d). Further work has been completed comparing ECMWF and EEVP vertical profiles of specific humidity and temperature. Minimal differences were observed (on the order of $0.01 \mathrm{~g} \mathrm{~kg}^{-1}$ and $0.01^{\circ} \mathrm{C}$, respectively). These findings lead us to believe that model dynamics are not significantly altered by this change made to RegCM3. Figure 5c displays the actual difference (in millimeters) of rainfall that is evaporated from ECMWF in the EEVP simulation. Encouragingly, the areas in the domain where RegCM3 significantly overestimates precipitation are the same areas where most precipitation evaporates (cf. Figs. 3b and 5c). For example, over the coastlines of the Black and Caspian Seas and the Zagros Mountains, nearly $500 \mathrm{~mm}$ of rainfall evaporates in EEVP. In addition, note the large amount of rainfall that has evaporated over the Arabian Peninsula and Persian Gulf coast, where a significant wet bias previously occurred in the model (Fig. $5 c)$. As a result, moving farther south in the domain to the lands of the hot and arid Syrian and Arabian Deserts, an increase in the percentage of total rainfall that evaporates is clearly visible (see Fig. 5d). That is, in parts of Saudi Arabia more than a third of the total rainfall simulated by $\mathrm{RegCM} 3$ in earlier simulations is evaporated in EEVP. Therefore, by incorporating this new evaporation scheme, significant differences in rainfall totals are clearly noticeable.

\section{1) COMPARISON TO CRU}

As seen in Figs. 7a and 7b, both NCEP and ECMWF simulations contain large biases of 44.1 and $37.8 \mathrm{~mm}$ $\mathrm{yr}^{-1}$. With our improvements to evaporation in RegCM3, EEVP's bias is reduced by $21 \mathrm{~mm}$ (or 16\%) to $16.9 \mathrm{~mm} \mathrm{yr}^{-1}$. More specifically, in the five years in which ECMWF overestimates CRU annual rainfall by 


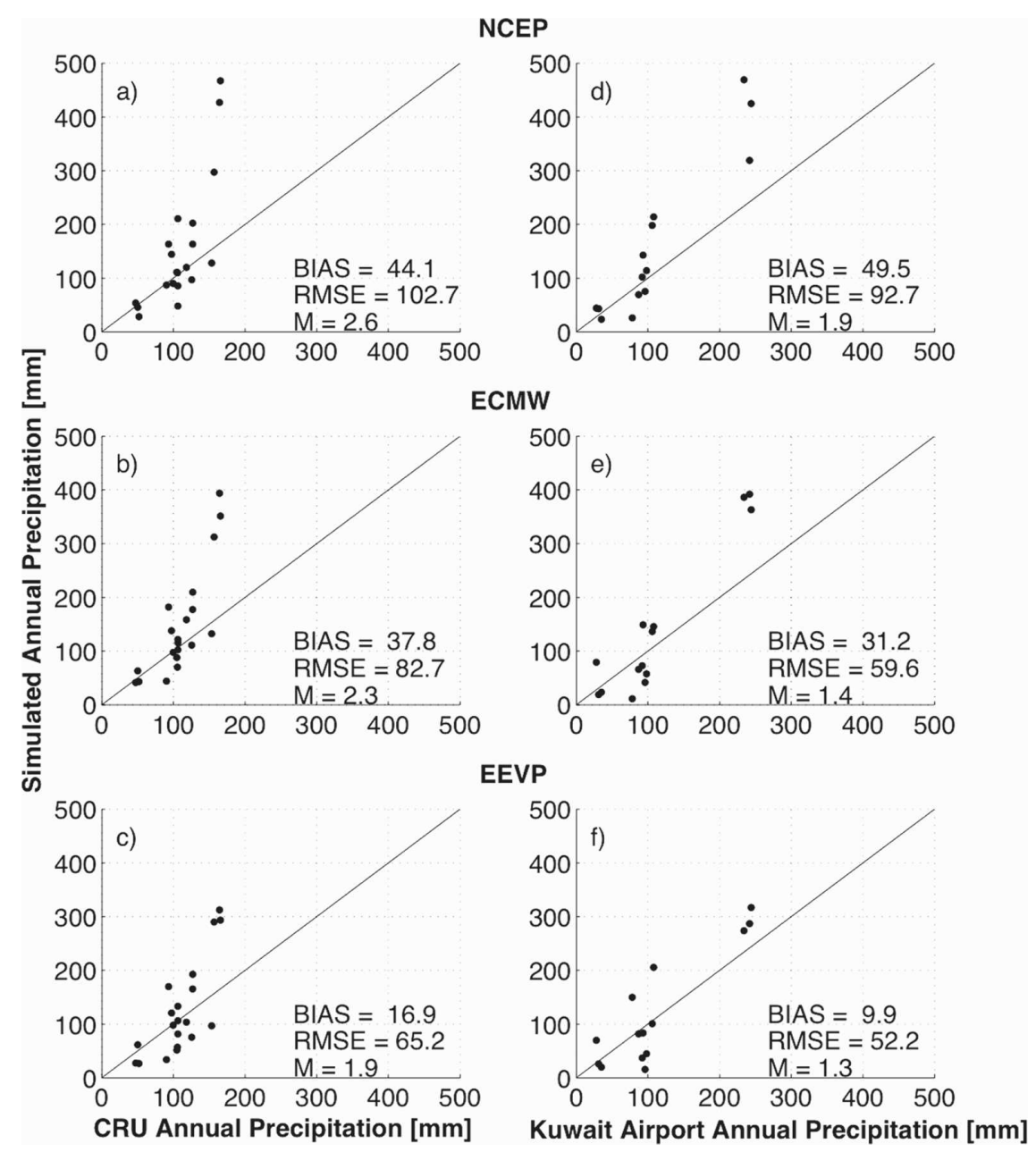

FIG. 7. For entire country of Kuwait, a scatterplot of CRU observations vs simulated annual rainfall in (a) NCEP, (b) ECMWF, and (c) EEVP simulation. Also, a scatterplot of annual rainfall from WMO Kuwait (City) Airport rain gauge data vs (d) NCEP, (e) ECMWF, and (f) EEVP simulations. Also listed are summary statistics (bias, rmse, M) for each simulation compared to observations. Note that comparisons between WMO and simulations are for 14 yr between 1982 and 2002, for which WMO had a complete rainfall record.

the largest amounts, EEVP reduces each of these values significantly. This trend is clearly seen in Fig. 6a. For example, in the wet years of 1992, 1997, and 2000, EEVP values fall much closer to CRU or GPCP obser- vations. As mentioned prior, $\mathrm{RegCM} 3$ has difficulty in accurately capturing years in which Kuwait's annual rainfall is well above average. This trend is further observed in other simulations performed with the model

TABLE 4. Summary statistics for country of Kuwait (simulations vs CRU) and Kuwait City International Airport (vs WMO). Bias in $\mathrm{mm}$, rmse in $\mathrm{mm}$, the slope of the best fit line $(M)$, and the $y$ intercept $(B)$ are presented. Values provided are for the period of 1982-2002 when observations were available from the airport (14 yr).

\begin{tabular}{|c|c|c|c|c|c|c|c|c|}
\hline & \multicolumn{4}{|c|}{ Simulations vs CRU } & \multicolumn{4}{|c|}{ Simulations vs WMO } \\
\hline & Bias & RMSE & $M$ & $B$ & Bias & RMSE & $M$ & $B$ \\
\hline CRU & - & - & - & - & -12.2 & 39.2 & 0.51 & - \\
\hline NCEP & 44.1 & 102.7 & 2.6 & -136.5 & 49.5 & 92.7 & 1.9 & -46.2 \\
\hline ECMWF & 37.8 & 82.7 & 2.3 & -110.4 & 31.2 & 59.6 & 1.4 & -13.5 \\
\hline EEVP & 16.9 & 65.2 & 1.9 & -90.5 & 9.9 & 52.2 & 1.3 & -19.8 \\
\hline
\end{tabular}


not included in this study. We believe that a positive feedback between evapotranspiration in prior time steps and subsequent moisture convergence causes this excessive rainfall. More specifically, as evapotranspiration occurs (from prior rainfall events), more and more of it indirectly contributes to ensuing moisture convergence and, hence, rainfall events. Therefore, by reducing the amount of precipitation that reaches the surface initially, EEVP curbs this precipitation recycling by redistributing this moisture aloft and across different grid cells in the model. As a result, EEVP's simulated annual rainfall of $126 \mathrm{~mm}$ is closest to CRU observations. Also encouraging is the fact that adding this improved evaporation scheme does not reduce dry years (annual rainfall less than $50 \mathrm{~mm}$ ) too drastically. Only twice do EEVP values fall significantly below observations or other simulations. Additionally, the interannual variability of EEVP $(88 \mathrm{~mm})$ is $13 \%$ lower than that of ECMWF (101 mm). As a result, an improvement is also made to the rmse and slope (see Fig. 7c). In short, EEVP's smaller bias means it is able to produce mean observational values better than NCEP or ECMWF. In addition, EEVP's 20\% reduction in rmse to $65.2 \mathrm{~mm}$ $\mathrm{yr}^{-1}$ and slope of under 2 (1.9) suggests that this simulation better represents the year-to-year variation in Kuwait rainfall. Finally, from Fig. 7c it is clearly seen that EEVP's scatter of points lies closest to the one-toone line of all simulations. Thus, EEVP performs best in simulating the overall hydroclimatology of Kuwait.

\section{2) Comparison to WMO}

Since large differences occur in annual rainfall totals between GPCP and CRU, WMO data are also used in comparing simulations' yearly means. The closest grid box to Kuwait City Airport in RegCM3 simulations is compared to airport rain gauge data (WMO). From Figs. $7 \mathrm{e}$ and $7 \mathrm{f}$, one can see that RegCM3 forced with ERA-40 boundary conditions performs better against WMO than against CRU. That is, both RegCM3 simulations (ECMWF and EEVP) contain smaller biases, rmse, and slopes for the comparison at the airport (see Table 4). This is due mostly to rain gauge values that are larger than CRU measurements for this locale. Nevertheless, as is apparent in Fig. 7e, ECMWF still contains a large bias of $31.2 \mathrm{~mm} \mathrm{yr}^{-1}$. This wet bias is mostly caused by RegCM3's difficulty in accurately capturing heavy rainfall years. For example, the wettest three years in WMO are substantially overestimated by ECMWF. By including our modified and new evaporation schemes, EEVP dramatically decreases total rainfall in each of these wet years (Fig. 7f). Moreover, four out of the five wettest simulated years in ECMWF have a significant reduction in total rainfall in EEVP. This decrease leads to a dramatic reduction in the bias to 9.9 $\mathrm{mm} \mathrm{yr}^{-1}$, producing simulations within $9 \%$ of observations. Last, with our new evaporation scheme, gains in the rmse, slope, and interannual variability are made. For example, EEVP exhibits the lowest rmse $(52.2 \mathrm{~mm}$ $\mathrm{yr}^{-1}$ ) and slope (M) of 1.3 (Table 4). Furthermore, it is clearly seen in Fig. $7 \mathrm{f}$ that EEVP's scatter of points also lies closest to the one-to-one line of all simulations performed. Therefore, compared to NCEP and ECMWF, EEVP does significantly better in predicting not only Kuwait's annual rainfall but also the annual variation in rainfall.

\section{Summary and conclusions}

By implementing and improving a simple, but physically based, subcloud layer evaporation scheme, RegCM3's rainfall performance over a semiarid region has been improved. More specifically, by incorporating dynamic evaporation, the model shows a strong response to rainfall evaporation in subcloud layers. As a result, mean model results are now substantially closer to observational datasets. For example, EEVP results are now within $15 \%$ of CRU observations for Kuwait's mean annual rainfall as shown in Fig. 8. Furthermore, model biases have dropped from nearly 45 to $16 \mathrm{~mm}$ $\mathrm{yr}^{-1}$. This improvement is noted all along the Arabian Peninsula where previously a large wet bias in rainfall was simulated by RegCM3 (cf. Figs. $3 \mathrm{~b}$ to $8 \mathrm{a}$ and $3 \mathrm{~d}$ to $8 b)$. Therefore, we confirm that subcloud layer evaporation is indeed an important physical process in simulating the mean hydroclimatology of arid regions.

In addition to strides made in annual rainfall totals, simulations of year-to-year fluctuations in Kuwait rainfall have also been substantially improved. By implementing ERA-40 boundary conditions and incorporating dynamic evaporation schemes, interannual variability as well as root-mean-square errors are significantly reduced (Table 4). More specifically, a 36\% reduction in rmse and $25 \%$ reduction in interannual variability occur between NCEP and EEVP. Furthermore, incorporating a dynamic evaporation scheme (EEVP) reduces the rmse value for Kuwait by an additional 17.5 $\mathrm{mm} \mathrm{yr}^{-1}$. Thus, we show that, along with ERA-40 boundary conditions, including subcloud layer evaporation in RegCM3 improves the accuracy of simulated rainfall interannual variability in semiarid climates. Encouragingly, we now observe rainfall totals that fall in between CRU rain gauge data and GPCP satellite measurements (Fig. 6). For example, as seen in Fig. 6b, EEVP falls between WMO and GPCP totals for most years, particularly the wet years of 1992, 1995, and 1997. Although values now lie closer to these observational 
EEVP Bias

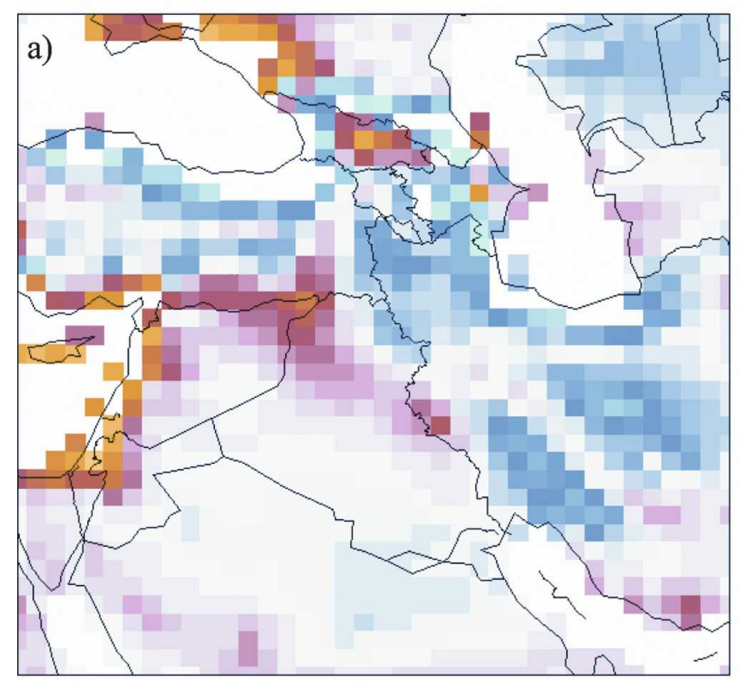

EEVP Percent Bias

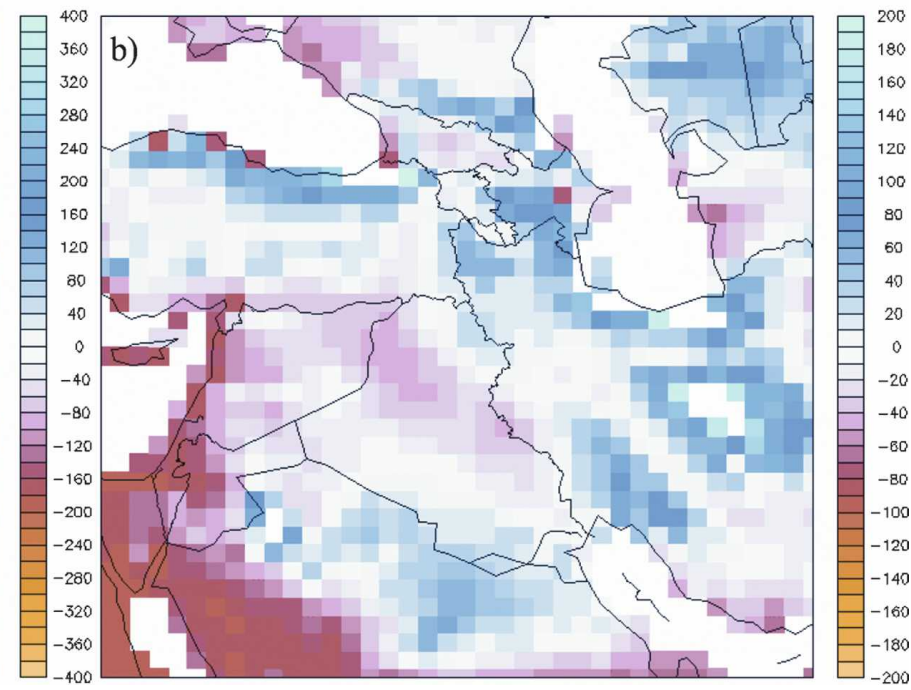

FIG. 8. Annual precipitation differences between CRU observations and EEVP simulations in (a) total difference (mm) and (b) percent of total CRU observations.

datasets, the inaccuracy of RegCM3 in simulating interannual variability of rainfall is one area still in need of improvement.

Finally, the discrepancy or wide range in values for observation datasets that describe Kuwait's rainfall distribution needs explanation. In general, for years with above-average rainfall, WMO totals are larger than those of CRU. These larger values are due to localized convective events occurring at the airport, which are muted in the CRU averaging (Al Kulaib 1984). In contrast, in dry years, WMO values are smaller than those of CRU. In these years, rainfall is most likely associated with northerly large-scale depressions that travel across Kuwait and areas farther north (Al Kulaib 1984). Therefore, CRU estimates, which have contributions from stations north of Kuwait (where a denser network of observations exists), overestimate the actual Kuwait rainfall in such years. Hence, it is of particular importance to include a comparison of model results to the WMO data. While both datasets have similar mean values, WMO contains a much larger standard deviation than CRU, 74 versus $40 \mathrm{~mm}$ (Table 3). As a result, the coefficient of variation for WMO is nearly $65 \%$ larger than that of CRU, demonstrating the large smoothing that occurs in CRU averaging over multiple stations. In contrast, GPCP mean estimates are consistently larger than both CRU and WMO data. This difference is partly due to GPCP's coarse resolution and use of satellite measurements for rainfall estimates. With a grid box over $250 \mathrm{~km}$ in resolution, GPCP estimates the rainfall over the Persian Gulf and the coast of Iran, whereas CRU and WMO are land-based estimates at much finer resolutions $(56 \mathrm{~km}$ and point estimate, respectively). Therefore, GPCP's estimate for Kuwait represents a larger area that includes regions where annual rainfall is significantly larger than Kuwait, as can be discerned from plots of rainfall distribution in the region (Fig. 2). However, as seen in Fig. 6b, when huge discrepancies do occur between CRU and GPCP, airport rain gauge data consistently fall in between the two datasets. Therefore, the comparison made in this study using both CRU and WMO as benchmarks is the best possible analysis for Kuwait rainfall.

This modified version of RegCM3 represents a model that can be implemented to better simulate natural climate variability across arid and semiarid climates. As a result, this tool can be used to produce more accurate predictions of changes in rainfall patterns induced by anthropogenic activity in such regions. Future work includes a more thorough examination of the existing formulation for rainfall evaporation. For example, using the actual vapor pressure deficit in calculating rainfall evaporation (in lieu of the relative humidity deficit) could improve model results further. In such a scheme, the saturation vapor pressure, which has a strong nonlinear dependence on temperature, is explicitly accounted for in deriving rainfall evaporation. Results from such a formulation will be documented in the near future.

Acknowledgments. The authors are grateful to all members of the Eltahir group and M.I.T. Parsons 
Laboratory who contributed in some way to this work. In particular, we are especially thankful to Jonathan Winter, whose technical assistance and valuable insight made this work possible. In addition, we are grateful to Jeremy Pal at ICTP for his feedback, guidance, and helpful suggestions along the way as well as two anonymous reviewers. This work has been funded through support by the Kuwait Foundation for the Advancement of Science.

\section{REFERENCES}

Adler, R., and Coauthors, 2003: The Version-2 Global Precipitation Climatology Project (GPCP) monthly precipitation analysis (1979-present). J. Hydrometeor., 4, 1147-1167.

Al Kulaib, A., 1984: The Climate of Kuwait. Al Ressala Press, 178 pp.

Al-Rashed, M. F., and M. M. Sherif, 2000: Water resources in the GCC countries. Water Resour. Manage., 14, 59-75.

Davies, H., and R. Turner, 1977: Updating prediction models by dynamical relaxation: An examination of the technique. Quart. J. Roy. Meteor. Soc., 103, 225-245.

Dickinson, R., A. Henderson-Sellers, and P. Kennedy, 1993: Biosphere Atmosphere Transfer Scheme (BATS) version 1e as coupled to the NCAR Community Climate Model. NCAR Tech. Note NCAR/TN-387+STR, 72 pp.

Evans, J., R. Oglesby, K. Maasch, and R. Smith, 2002: Investigation of Middle Eastern climate using a regional climate model. Preprints, 13th Symp. on Global Change and Climate Variations, Orlando, FL, Amer. Meteor. Soc., 4.6. [Available online at http://ams.confex.com/ams/pdfpapers/29690.pdf.]

_ R. Smith, and R. Oglesby, 2004: Middle East climate simulation and dominant precipitation processes. Int. J. Climatol., 24, 1671-1694.

Fadlelmawla, A., and M. Al-Otaibi, 2005: Analysis of the water resources status in Kuwait. Water Resour. Manage., 19, 555570.

Georgakakos, K. P., and R. L. Bras, 1984: A hydrologically useful station precipitation model: 1. Formulation. Water Resour. Res., 20, 1585-1597.

Giorgi, F., M. Marinucci, and G. Bates, 1993a: Development of a second-generation regional climate model (RegCM2). Part I: Boundary-layer and radiative transfer processes. Mon. Wea. Rev., 121, 2794-2813.

$\longrightarrow,-$, G. Bates, and G. De Canio, 1993b: Development of a second-generation regional climate model (RegCM2). Part II: Convective processes and assimilation of lateral boundary conditions. Mon. Wea. Rev., 121, 2814-2832.

—, L. Mearns, C. Shields, and L. McDaniel, 1998: Regional nested model simulations of present day and 2xCO2 climate over the central Great Plains of the United States. Climatic Change, 40, 457-493.

Grell, G., J. J. Dudhia, and D. Stauffer, 1994: A description of the fifth-generation Penn State/NCAR Mesoscale Model (MM5). NCAR Tech. Note TN-398+STR, 138 pp.

Holtslag, A., E. de Bruijn, and H. Pan, 1990: A high-resolution air mass transformation model for short-range weather forecasting. Mon. Wea. Rev., 118, 1561-1575.
Jiao, Y., and D. Caya, 2006: An investigation of summer precipitation simulated by the Canadian Regional Climate Model. Mon. Wea. Rev., 134, 919-932.

Kalnay, E., and Coauthors, 1996: The NCEP/NCAR 40-Year Reanalysis Project. Bull. Amer. Meteor. Soc., 77, 437-471.

Kiehl, J., J. Hack, G. Bonan, B. Boville, B. Breigleb, D. Williamson, and P. J. Rasch, 1996: Description of the NCAR Community Climate Model (CCM3). NCAR Tech. Note TN$420+$ STR, 152 pp. [Available online at http://www.cgd.ucar. $\mathrm{edu} / \mathrm{cms} / \mathrm{ccm} 3 / \mathrm{TN}-420 /$.

Kuo, H., 1974: Further studies of the parameterization of the influence of cumulus convection on large-scale flow. $J$. Atmos. Sci., 31, 1232-1240.

Mageed, Y. A., 1994: The central region: Problems and perspectives. Water in the Arab World: Perspectives and Prognoses, P. Rogers and P. Lydon, Eds., Harvard University Press, 101120.

Mitchell, T. D., and P. D. J. Jones, 2005: An improved method of constructing a database of monthly climate observations and associated high-resolution grids. Int. J. Climatol., 25, 693-712.

Mukhopadhyay, A., A. Akber, E. Al-Awadi, and N. Burney, 2000: Analysis of freshwater consumption pattern in Kuwait and its implication for water management. Int. J. Water Resour. Dev., 16, 543-561.

Pal, J., E. Small, and E. A. B. Eltahir, 2000: Simulation of regional-scale water and energy budgets: Representation of subgrid cloud and precipitation processes within RegCM. $J$. Geophys. Res., 105, 29 579-29 594.

_ , and Coauthors, 2007: Regional climate modeling for the developing world: The ICTP RegCM3 and RegCNET. Bull. Amer. Meteor. Soc., 88, 1395-1409.

Pruppacher, H., and J. Klett, 1978: Microphysics of Clouds and Precipitation. D. Reidel, 714 pp.

Reynolds, R. W., N. Rayner, T. Smith, D. Stokes, and W. Wang, 2002: An improved in situ and satellite SST analysis for climate. J. Climate, 15, 1609-1625.

Rosenfeld, D., and Y. Mintz, 1988: Evaporation of rain falling from convective clouds as derived from radar measurements. J. Appl. Meteor., 27, 209-215.

Small, E., F. Giorgi, and L. Sloan, 1999: Regional climate model simulation of precipitation in central Asia: Mean and interannual variability. J. Geophys. Res., 104D, 6563-6582.

Sundqvist, H., E. Berge, and J. Kristjánsson, 1989: Condensation and cloud parameterization studies with a mesoscale numerical weather prediction model. Mon. Wea. Rev., 117, 16411657.

Syed, F., F. Giorgi, J. Pal, and M. King, 2006: Effect of remote forcings on the winter precipitation of central southwest Asia. Part 1: Observations. Theor. Appl. Climatol., 86, 147160.

Uppala, S., and Coauthors, 2005: The ERA-40 Re-Analysis. Quart. J. Roy. Meteor. Soc., 131, 2961-3012.

Worden, J., D. Noone, and K. Bowman, 2007: Importance of rain evaporation and continental convection in the tropical water cycle. Nature, 445, 528-532.

Zeng, X., M. Zhao, and R. Dickinson, 1998: Intercomparison of bulk aerodynamic algorithms for the computation of sea surface fluxes using TOGA COARE and TAO data. J. Climate, 11, 2628-2644. 